\title{
Metrics of Unrest: Building Social and Technical Networks for Heathrow Noise
}

\section{Christian Nold}

\begin{abstract}
This chapter describes Christian Nold's research with Hubbub, which started with working around Heathrow Airport in London and encountering the way local people are affected by the noise there. To understand the controversies concerning the impact of aircraft noise at Heathrow, it is necessary to understand the way technical metrics can systematically exclude the experience of local people. Christian seeks to address this exclusionary combination of technology and politics by building a new noise-monitoring network for Heathrow that engages equally with the social and technical aspects of noise and sees them as fundamentally intertwined.
\end{abstract}

Keywords Airport · Interdisciplinary · London · Participatory · Prototype · Sound

The problem of aircraft noise at Heathrow Airport in London dates back to the introduction of turbojet aircraft in 1958. Today, noise is still the key issue at the centre of discussions about possible airport expansion through a third runway. While proponents argue that expansion is needed

\footnotetext{
C. Nold $(\bowtie)$

University College London, London, United Kingdom

e-mail: christian@softhook.com

(C) The Author(s) 2016

F. Callard et al. (eds.), The Restless Compendium, DOI 10.1007/978-3-319-45264-7_18
} 
to support growth, ${ }^{1}$ opponents argue that it will dramatically increase air and noise pollution for local residents. ${ }^{2}$ For politicians, the decision on whether to expand is seen as a 'toxic dilemma' ${ }^{3}$ that is likely to alienate large parts of the electorate. As the impact of noise on human health extends well beyond hearing loss, to include increased risks of hypertension and heart disease, in addition to sleep disturbances (including daytime sleepiness), this is also a significant public health issue. ${ }^{4, \mathrm{i}}$

Despite this political dilemma, the governance of noise at the airport has not really changed for the last $\mathbf{5 0}$ years. It is focused on a 'community annoyance' metric that quantifies the impact of noise on local residents. The current metric was created in 1982 and is based on interviews with just 2,097 residents who were asked how bothered they were by noise in the area, on a scale from 'very much' or 'moderately' to 'a little' or 'not at all'. This stated level was compared to measured sound pressure to create a curve relationship between people's stated experience and sound pressure. Based on this relationship, a threshold was identified at $57 \mathrm{~dB}$ LAeq, 16h, which was said to represent the 'onset of significant community annoyance'. 5 This threshold was then plotted as a contour around the airport. People living within the contour band are said to be affected by aircraft noise, for purposes such as subsidized sound insulation, while those outside it are not. Crucially, the number of people living within the annoyance contour is a key battleground in the debate over whether Heathrow should be expanded. If it can be demonstrated that the number of annoyed people would not change or might go down with a third runway, then support from the politicians is more likely to be forthcoming.

Yet many residents are extremely frustrated with the way this metric flattens and marginalizes their experience. ${ }^{\text {ii }}$ A particular point of contention is the way the metric averages noise peaks, and does not represent the disruptiveness of very loud aircraft every 90 seconds. The $2 \mathrm{M}$ group of local authorities also argues that the current annoyance metric systematically excludes nearly a million residents who are actually affected by aircraft noise. ' $M e m b e r$ of the Public 16' provided the following stakeholder response to the Airports Commission discussion paper:

Heathrow are also exploiting the $57 \mathrm{~dB}$ noise threshold to make it look like there is a reduction in noise with an expanded airport. The reality of course

\footnotetext{
${ }^{i}$ Cf. Chap. 12.

ii See Chaps. 6 and 11.
} 
is that noise continues to be hugely disturbing to many people considerably below that threshold, me included. Where I currently live whilst better than Kew (hence I moved here) and just outside the $57 \mathrm{~dB}$ contour is still disturbing enough to wake my children regularly. ${ }^{7}$

Even acousticians agree that these annoyance metrics are out of date, largely arbitrary and merely a convenient way for governments to deal with the political problem of noise. Many residents have expressed a desire for a grass-roots process to document the reality of the noise. While there is a well-organized and active Heathrow noise pressure group called Heathrow Association for the Control of Aircraft Noise (HACAN), its focus has been on opposing expansion using political and economic arguments rather than focusing on noise monitoring. The problem is that the official hardware used for static noise monitoring is extremely expensive, and out of the reach of a distributed community noise-monitoring network. This has meant that some residents have privately paid companies to carry out a noise survey of their home. Unfortunately, these surveys have usually been short term and not had any political impact. What is missing is an independent noise-monitoring network focused on Heathrow Airport.

For the last two years I have been organizing just such a sound-monitoring network to engage with the challenge posed by the current noise metrics. The immediate goal has been an experimental network of prototypes that could function as an exemplar and encourage others to build a large-scale network with many devices and participants. The long-term goal is to set up a public process of developing an alternative metric that could take better care of the experience of local residents.

Building the network involved creating institutional relationships with Windsor and Maidenhead Council and the pressure group HACAN, both of which gave strategic advice and put me in touch with their members. It also involved public workshops and events to engage Heathrow residents in brainstorming and co-designing concepts, hardware and software. In the workshops, participants experimented with prototype devices and discussed new approaches for dealing with the annoyance metric. From these workshops the main conclusion was the need to build a network that would represent the diversity and multiplicity of noise impacts. Based on these observations, I extended the network to include sound artists and academics working on the effects of noise on biodiversity. 
The hardware prototype that emerged from this process is a small computer with a calibrated measurement microphone (Fig. 18.1). People who feel they are affected by aircraft noise can place the device in their garden to measure and broadcast the impact of noise (Fig. 18.2). The device is

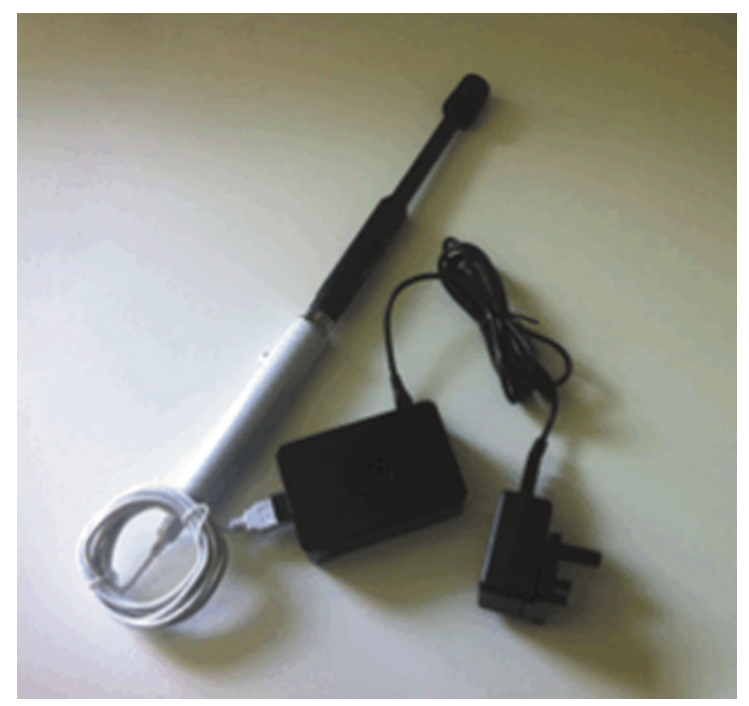

Fig. 18.1 Small computer with calibrated measurement microphone (Photograph by Christian Nold)

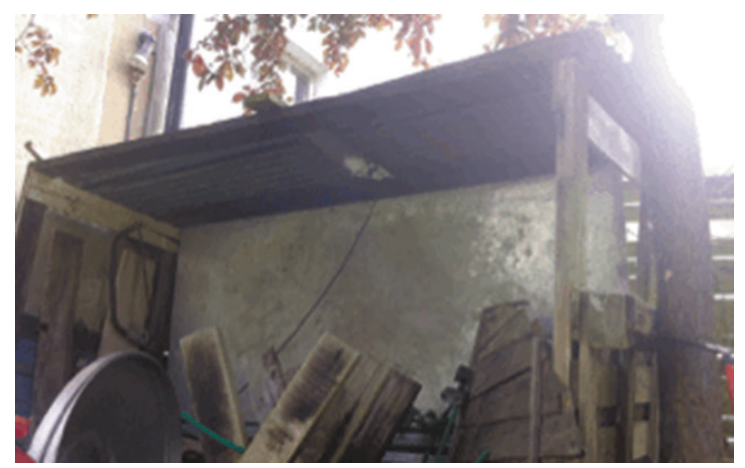

Fig. 18.2 Prototype noise-monitoring device installed in a garden in Windsor (Photograph by Christian Nold) 
designed to be cheap $(£ 120)$ while being sufficiently accurate enough to produce data that are comparable to the official noise metrics. Data are uploaded to an online public repository where they can be viewed as a time-series graph. Yet crucially, in addition to this, the device creates a sound stream that is available as a real-time internet radio station, allowing listeners to experience the local audio as a soundscape. ${ }^{8}$

There are currently three prototypes in operation, with the oldest in Windsor having collected, at the point of writing, almost a year of data. The Windsor device is $6.5 \mathrm{~km}$ west of the Heathrow runways; another is in Hanwell, $9.5 \mathrm{~km}$ east of the runways; and the last is in Camberwell, $24 \mathrm{~km}$ from the runways. What is interesting is that the aircraft are extremely disruptive at all these locations, even though only two are within the demarcated annoyance contour. The Windsor device is hosted by one of the project teams who has developed special software to analyse the decibel data. This has allowed the identification of disruptive out-of-hours flights by correlating night-time peaks with third-party aircraft data, and has enabled targeted complaints to be made to the National Air Traffic Services and an air force base. The prototype data have also been used to monitor the airport's own assertion that 'Heathrow is getting quieter'.' The airport makes this claim based on graphs that indicate a shrinking of the annoyance contour. My intention is that the prototypes will be able to collect long-term empirical data that could challenge this claim by demonstrating changes in the overall noise levels within and outside the annoyance contour boundaries. Environmental officers from Windsor and Maidenhead council and the Aviation Forum have already used the prototype data, but more time and data are needed from the other devices to make an overall argument about whether Heathrow is becoming louder or quieter.

The internet radio station aspect of the prototype has enabled people who live well outside the noise contours to listen to the soundscape of Heathrow. In this way, the noise of the aircraft is treated as not just a pollutant but also something that has sonically interesting dynamics that people might want to actively listen to. iii The real-time broadcast has allowed me to create an installation where members of the public could compare the soundscapes at Windsor and Camberwell. While many people expected to hear aircraft, a surprising range of other sounds were audible, including birds, rustling leaves, domesticated chickens and children playing. These

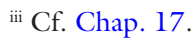


were often interrupted by the noise of the aircraft, experienced as loud, low-frequency growls that would often trigger the screeching of birds. Even after the noise of the aircraft dispersed, it was possible to hear the lingering after-effects on the birds in their continued squawking. I have had discussions about this with a wildlife expert, who mentioned that although there are studies addressing the way that birds adapt to traffic noise by singing more loudly and at higher pitch, he was not aware of any study looking at the effect of intermittent loud noise on wildlife.

The devices created a tangible experiential connection to the constant sonic effects of Heathrow. Many visitors to the installation were surprised at how frequent and loud the aircraft were even in Camberwell, which is $24 \mathrm{~km}$ from the runways. It became clear that Heathrow has a dramatic impact on the whole of London, well beyond its demarcated noise contours. For many of the visitors, this was the first time they had paid any active attention to aircraft sound. By listening closely, they could attend to the sonic qualities of the aircraft at different heights and judge whether the aircraft were coming towards the devices. The people who were hosting the prototypes were also present at the installation, and many visitors were keen to engage them in discussions about the experiential effects of having to live with this noise every day, as well as the political implications of a third runway at Heathrow. During the event, a number of visitors expressed an interest to join the noise-monitoring network and host a device in their own garden.

The prototypes have demonstrated the impact of a social and technical network that can engage with a contentious issue by collecting empirical data for official complaints, as well as develop a means of contesting broader claims about long-term changes in pollution management. In this way, the prototypes represent the first step towards developing an alternative public metric for noise at Heathrow. At the same time, the prototypes have demonstrated that it is possible to sensitize a previously unaffected audience to these environmental and health impacts and bring them into a more intense engagement with the context. For this network to grow and have a transformative impact on the situation at Heathrow, more work is required to engage with local residents, as well as institutional entities such as local councils and the airport itself. Moreover, further research needs to be done on alternative conceptual models for representing the impact of noise as metrics, which means developing new hardware and software.

The overall approach must maintain multiple ways of representing and broadcasting sound in order to bring new and surprising actors into the 
Heathrow situation. If this multiplicity is sustained, the network has the potential to bring radically different disciplines into its orbit, from ornithology to the neurosciences, thus adding new evidence bases to the political discussion around Heathrow.

Acknowledgements I would like to acknowledge the support of Andrew Hall, Grant Smith, Max Baraitser Smith and Matthias Stevens in carrying out this research.

\section{Notes}

1. Airports Commission, 'Airports Commission: Final Report' (London: Airports Commission, 2015), https://www.gov.uk/government/uploads/ system/uploads/attachment_data/file/440316/airports-commission-final-report.pdf.

2. HACAN ClearSkies, 'HACAN ClearSkies', 2015, http://www.hacan.org. uk.

3. Laura Kuenssberg, 'Heathrow Airport Expansion: A "Toxic" Dilemma for Ministers', BBC News, October 19, 2015; accessed 27 June 2016, http:// www.bbc.co.uk/news/uk-politics-34568530.

4. Mathias Basner et al., 'Auditory and Non-auditory Effects of Noise on Health', Lancet 383, no. 9925 (2014): 1325-32.

5. Secretary of State for Transport, 'Aviation Policy Framework' (The Stationery Office, 2013), 58, https://www.gov.uk/government/uploads/ system/uploads/attachment_data/file/153776/aviation-policy-framework.pdf.

6. Airport Watch, '2M Group of Councils Call for New Study into Attitudes to Aircraft Noise', 8 September 2013, http://www.airportwatch.org. uk/2013/09/2m-group-of-councils-call-for-new-study-into-attitudes-toaircraft-noise.

7. Airports Commission, 'Member of the Public 16: Noise Discussion Paper', 2013,https://www.gov.uk/government/publications/stakeholder-responsesto-airports-commission-discussion-papers.

8. Christian Nold, 'Exhibition at the Wellcome Collection ['Heathrow Noise']'; see the livestream at http://www.softhook.com/heathrow/.

9. Heathrow Airport Limited, 'A Quieter Heathrow' (London: Heathrow Airport Limited, 2013), 14; http://www.heathrow.com/file_source/ HeathrowNoise/Static/a_quieter_heathrow_2013.pdf. 


\section{FurTher READing}

Le Masurier, Paul, J. Bates, J. Taylor, I. Flindell, D. Humpheson, C. Pownall, et al. 'Attitudes to Noise from Aviation Sources in England (ANASE): Final Report for Department for Transport'. Norwich: Her Majesty's Stationery Office, 2007.

Nold, Christian. 'Micro/Macro Prototyping'. International Journal of HumanComputer Studies. Transdisciplinary Approaches to Urban Computing 81, issue C (2015): 72-80.

Nold, Christian. Exhibition at the Wellcome Collection ['Heathrow Noise']. http://www.softhook.com/heathrow/. Accessed 27 June 2016.

Stewart, John, F. McManus, N. Rodgers, V. Weedon, and A. Bronzaft. Why Noise Matters: A Worldwide Perspective on the Problems, Policies and Solutions. Abingdon, Oxon and New York: Earthscan, 2011.

Christian Nold is an artist, designer and academic who builds participatory technologies for collective representation. In the last decade, he has created largescale public projects including 'Bio Mapping' and 'Emotion Mapping', which have been staged with thousands of participants across 16 countries.

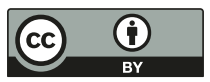

This chapter is distributed under the terms of the Creative Commons Attribution 4.0 International License (http://creativecommons.org/ licenses/by/4.0/), which permits use, duplication, adaptation, distribution and reproduction in any medium or format, as long as you give appropriate credit to the original author(s) and the source, a link is provided to the Creative Commons license and any changes made are indicated.

The images or other third party material in this chapter are included in the work's Creative Commons license, unless indicated otherwise in the credit line; if such material is not included in the work's Creative Commons license and the respective action is not permitted by statutory regulation, users will need to obtain permission from the license holder to duplicate, adapt or reproduce the material. 